\title{
Utilizing Unified Power Flow Controller for Voltage Stability Improvement of the Electric Power Transmission System of Ghana
}

\author{
William Duodu Asihene ${ }^{1}$, Francis Boafo Effah ${ }^{2 *}$ and Erwin Normanyo ${ }^{1}$ \\ ${ }^{1}$ Department of Electrical and Electronic Engineering, University of Mines and Technology, \\ Tarkwa, Western Region, Ghana \\ ${ }^{2}$ Department of Electrical and Electronic Engineering, Kwame Nkrumah University of Science and \\ Technology, Kumasi, Ashanti Region, Ghana \\ ${ }^{*}$ Corresponding author, e-mail: fbeffah.coe@knust.edu.gh
}

\begin{abstract}
Interconnecting power transmission systems provide reliability of electric power supply. The security of the system is however questioned when a disturbance in any part of the interconnected system causes instability in the entire network. Unified Power Flow Controller (UPFC), which is a member of the flexible alternating current transmission system (FACTS) family, has the capability of controlling active and reactive power flow in a transmission line thereby improving the voltage stability of the system especially at the $500 \mathrm{kV}$ configuration level. The performance of a $161-\mathrm{kV}$ UPFC modelled in SimPowerSystems is tested on Ghana's power transmission network. The optimal placement of the UPFC is done using fast voltage stability index (FVSI) and maximum loadability assessment (MLA). The results show that the device improved the connecting bus voltage from 0.88 p.u. to 0.98 p.u. Active power loss in the network was also reduced from $13.40 \mathrm{MW}$ to $10.39 \mathrm{MW}$ when the UPFC was in circuit.
\end{abstract}

Keywords: Ghana, Stability, Transmission system and Unified Power Flow Controller (UPFC)

\section{Introduction}

As demand in electricity grows, there is the need for more interconnections of power transmission systems. These complex interconnections provide low cost on power transmission and reliability [1]. Along with the positive impacts are the negative effects which threaten the reliability and security of these interconnected systems [2]. The authors in [3] identified the major problem associated with a power transmission system to be instability, where, a disturbance in any part of the power system may lead to either partial or total system collapse. The instability is determined based on the parameters affecting the power system. These can be categorised under rotor angle, frequency and voltage stability [4]. Even as frequency and rotor angle can be controlled locally from the generating stations, the action of over exciter limiters (OEL) prevents a complete control of voltage stability [5]. Voltage instability has caused a number of outages in power systems world-wide, and has been documented by [6].

A number of methods used to solve voltage stability problems have been discussed by [7], [8]
Among these methods are: coordination of protection and control systems, reactive power compensating devices, tap changing transformers, and operating an adequate reserve margin. Reactive power compensation through the use of flexible alternating current transmission system (FACTS) devices has become the most effective means of improving voltage stability of an interconnected power system [9]. FACTS devices have recently been used widely in weak power systems. They can control power flow during normal and abnormal operating conditions with the capability of improving system voltages by reducing power losses. The effect of these devices should however be assessed prior to their use to help achieve the optimum operating results [10].

A series of FACTS devices (SSSC and TCSC) to improve power system stability on a $500-\mathrm{kV}$ transmission line were implemented in [11]. The performance results of the implemented devices however demonstrated an unstable steady state condition without a power system stabilizer. The authors in [12] demonstrated the performance of different FACTS devices on an IEEE 9-bus system. The modelled network was subjected to a 
3-phase symmetrical fault. The results indicated that the shunt connected devices increased the reactive power loss in the system, whereas the series connected devices improved the voltage from 0.954 to $0.9612 \mathrm{~V}$. The UPFC however reduced the reactive power loss by $19.34 \%$ and improved the bus voltage to 1 p.u.

Comparisons made on different FACTS devices conclude that UPFC is the most versatile and has the tendency to provide a better stability margin, increase power transfer and improve system's reactive power deficiency [1], [13]. Authors in [14] used a $500 \mathrm{kV}$ UPFC model to improve voltage stability and control active power on a 5-bus power system. Authors in [15] concluded that a $500 \mathrm{kV}$ UPFC can optimize active power flow after a network fault. This approach was successfully tested on LuchengXin'an transmission line. Currently a lot of papers present the UPFC in a $500-\mathrm{kV}$ configuration. According to [16], the system operating voltage influences the power circuit design of the UPFC. Hence configuring the device with a different operating voltage opens a new area of research.

The random placement of UPFC in an interconnected power system can increase the burden on the system. There is therefore the need to find the optimal placement of the device in order to improve its efficiency. In assessing the effectiveness of the three major techniques for optimal placement of FACTS devices, [17] concluded that the sensitivity-based methods require solving a large system of equations, hence making them not conducive for multi-device placement into a large network. However, for a single FACTS device according to [18], it is efficient and convenient to find the optimal location using the sensitivity-based method. The conventional optimisation-based method (linear programming) has a lot of penalty algorithms and may not work for some types of variables.

The artificial-intelligence (AI) based methods are very expensive to implement because of complexity in implementation attributed to data and algorithm dependency demanding need for accurate training using readily available but secured, authentic and unbiased quality data; cost implications due to lack of a readily available skilled AI implementation community; and high dependency on processing speed of computing machines. It is also difficult and sometimes impossible to reach the optimal solution required by the objective function when AI and conventional optimization methods are used [19].

Authors in [20] used fast voltage stability index (FVSI) to find the optimal placement of UPFC in a 30-bus network. The search space and computational time was reduced using voltage profile enhancement indicator. Critical bus ranking index for the optimal placement of UPFC on a 5-bus network was used by authors in [21]. The critical buses in the network were identified and the UPFC was placed on the most severe bus. However, in dealing with voltage improvement, the weakest bus and the line with the heaviest loading must be identified to achieve the optimum placement of the FACTS device.

So far, the UPFC was deployed at operating voltages of $500 \mathrm{kV}$, but the $161 \mathrm{kV}$ model has not been studied. Also, studies on the Ghanaian network by [22], [23] made use of SVC and STATCOM, respectively to improve voltage stability, however in [22], Bolga and beyond in Upper East and in [23], interconnecting buses in exception of Tamale suffered voltage instabilities. This paper addresses the enumerated shortcomings and thus fills the knowledge gap on $161 \mathrm{kV}$ UPFC configuration in the Ghana power network. In this paper therefore, a $161-\mathrm{kV}$ model of an UPFC is presented and implemented on an 11-bus network. FVSI is used to identify the critical line and maximum loadability assessment (MLA) employed to find the weakest bus.

\section{Unified Power Flow Controller Model}

The UPFC used in this paper is modelled to effect changes in the parameters of a $161-\mathrm{kV}$ transmission line. It consists of two sets of voltage source converters (VSCs), with one set connected in shunt and the other in series to the transmission system using a set of specialized transformers. A simple UPFC model is shown in Fig. 1.

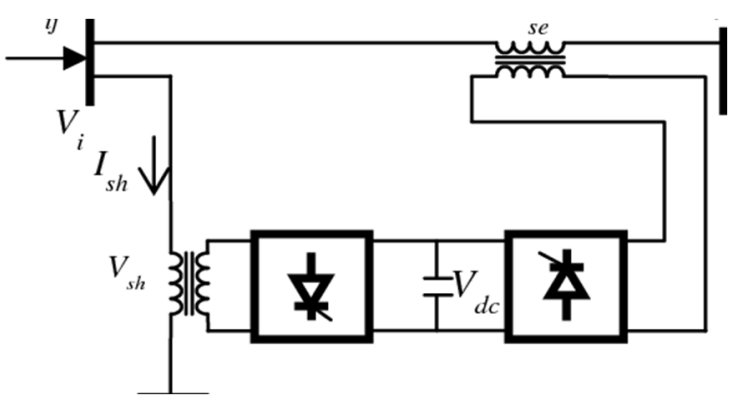

Fig. 1 Model of the UPFC 
The shunt inverter operates as a STATCOM and the series inverter operates as an SSSC, which are both coupled to a common DC link capacitor. A switch is connected between both sets of capacitors to enable the UPFC to operate in several modes. The opening and closing of the switch cause the device to either assume operation in the STATCOM, SSSC or UPFC mode. With both converters able to transfer active and reactive power through the common DC link capacitor, the injected voltage generated by the SSSC is not limited to stay in quadrature with the line current but can rather assume any angle with respect to the current, making it possible to transfer or absorb active and reactive power as well as to improve system voltages.

\section{Description of Test System}

The test system is modelled as the power system present at the northern section of Ghana's transmission network. The system consists of two generating sources and also contains 1090.4 circuit kilometers of $161 \mathrm{kV}$ transmission lines interconnecting eleven bulk supply points (BSPs) with 17 MVAr static capacitor banks at four different BSPs. This helps to verify the effectiveness of these devices on the improvement of voltage on the actual system.

\section{Methodology}

System data taken from Ghana's grid was used to model the power system in MATLAB Simscape Power Systems software (SimPowerSystems).

An overview of the software is presented by [24]. The system data is entered into the premodelled blocks of the software to depict the actual system. After the power system has been modelled, load flow analysis is performed to determine the state of the network before compensation. The power and control circuits of the UPFC are also modelled using the same software.

The high-power control of the $161-\mathrm{kV}$ network is achieved by using four GTO based square wave inverters of $100 \mathrm{MVA}$ at each side of a common DC link capacitor. The voltage produced by each inverter is applied to four phase-shifting transformers (each connected to one inverter) to eliminate harmonics to the $45^{\text {th }}$ level. The nominal power on each transformer is selected at 25 MVA at a frequency of $50 \mathrm{~Hz}$ and a turns ratio of 9.5 . With a surge impedance loading of 100 MVA and a voltage of $161 \mathrm{kV}$, the phase current derived is 358.6 A, which helps to determine the DC link capacitor rating as $4000 \mu \mathrm{F}$. The UPFC controller is designed in accordance with the description provided by [25]. The complete system model with UPFC optimally located is found in Fig 2.

To verify the results obtained from placing the UPFC at the optimal location, a modelled STATCOM is placed at the same location where the UPFC is placed and a comparison is made on their results.

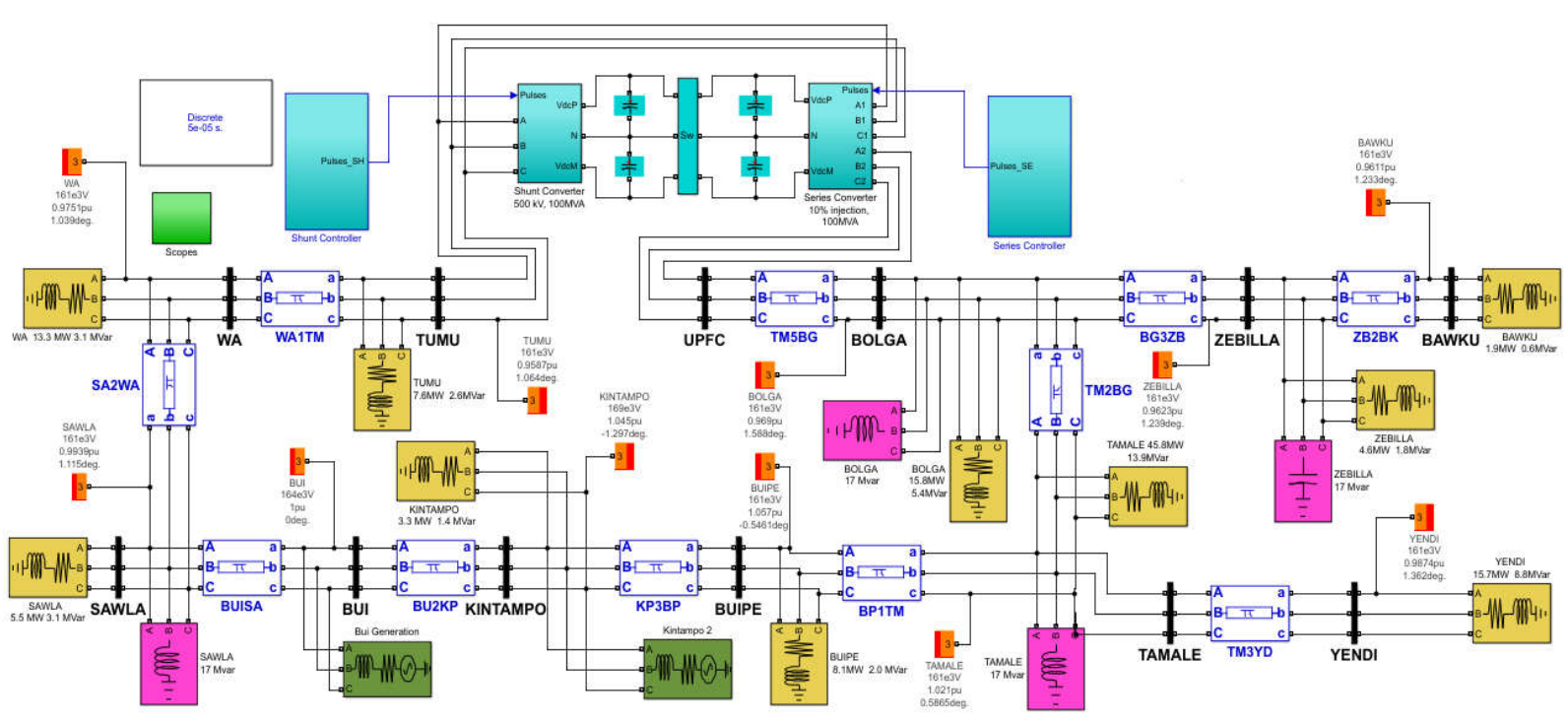

Fig. 2 The complete power transmission system model of the UPFC optimally located 
The optimal location of the UPFC is done by finding the weakest bus and the critical lines in the network. The weakest bus is identified using MLA by determination of maximum reactive power that each load bus in the network can tolerate without network collapse. In this regard, the bus with the least value of maximum reactive power is considered as the weakest bus. The adjoining critical line is determined using the FVSI. This index is determined using equation (1) as proposed by [26].

$$
\frac{4 Q_{r} Z^{2}}{V_{s}^{2} X} \leq 1
$$

where, $Q_{r}$ is receiving end reactive power in MVAr, $\mathrm{Z}$ is line impedance in ohms, $\mathrm{V}_{\mathrm{s}}$ is sending end voltage in volts, $X$ is line reactance in ohms.

The UPFC is then placed at the point where the critical line meets the weakest bus. The flowchart of Fig. 3 describes the procedure in determining the optimal location of the UPFC.

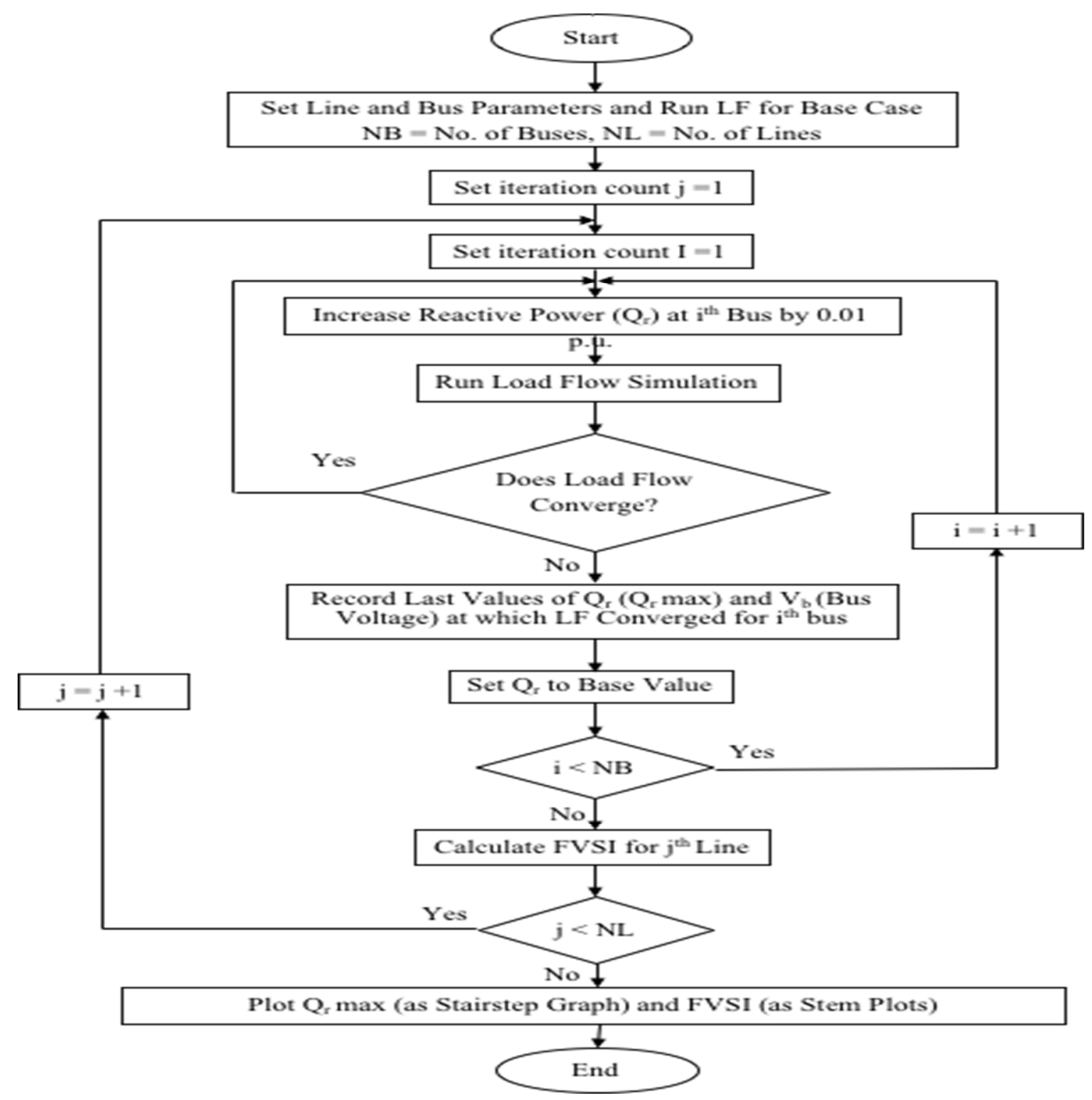

Fig. 3 Flowchart used to determine optimal location of UPFC

A write-up of the flowchart is as follows:
Step 1: Load system data and perform initial load flow studies for base case. 
Step 2: Select one bus and progressively increase its reactive power by 0.01 MVAr.

Step 3: Perform load flow studies for each increment until load flow solution fails to converge

Step 4: Record the last value of reactive power increment $\left(\mathrm{Q}_{\mathrm{r}}\right)$ and its corresponding adjoining bus voltage, $\left(\mathrm{V}_{\mathrm{s}}\right)$ at which load flow converges. This indicates the maximum reactive power (maximum loadability), above which voltage collapse may occur on the said bus.

Step 5: Repeat steps (ii) to (iv) until all buses have been selected.

Step 6: Insert $\mathrm{Q}_{\mathrm{r}}$ and $\mathrm{V}_{\mathrm{s}}$ into (1) and determine the FVSI for each line

Step 7: Sort the maximum loadability, $\mathrm{Q}_{\mathrm{r}}$ in ascending order. The bus with the least value is ranked the weakest bus.

Step 8: The line with the highest value of FVSI is the most critical line, which is capable of causing voltage collapse.

\section{Results and Discussions}

The results obtained from simulating the modelled system are presented in this section. The FVSI and MLA results are presented in Table 1 and Fig. 4 shows the outcome of load flow voltages with UPFC, STATCOM and with no device in circuit.

Table 1. Results of FVSI and MLA

\begin{tabular}{|c|c|c|c|c|}
\hline Line & Line ID & FVSI & Bus & MLA(Mvar) \\
\hline $\begin{array}{c}\text { Kintampo } \\
\text { - Buipe }\end{array}$ & KP3BP & 0.0934 & BUIPE & 2452 \\
\hline $\begin{array}{c}\text { Buipe - } \\
\text { Tamale }\end{array}$ & BP1TM & 0.1548 & TAMALE & 546 \\
\hline $\begin{array}{c}\text { Tamale - } \\
\text { Bolga }\end{array}$ & TM2BG & 0.0846 & BOLGA & 14.4 \\
\hline $\begin{array}{c}\text { Bui - } \\
\text { Sawla }\end{array}$ & BU1SA & 0.0357 & SAWLA & 54.1 \\
\hline $\begin{array}{c}\text { Tamale - } \\
\text { Yendi }\end{array}$ & TM3YD & 0.0298 & YENDI & 24.9 \\
\hline $\begin{array}{c}\text { Bolga - } \\
\text { Zebilla }\end{array}$ & BG3ZB & 0.0074 & ZEBILLA & 10.9 \\
\hline $\begin{array}{c}\text { Zebilla - } \\
\text { Bawku }\end{array}$ & ZB2BK & 0.0050 & BAWKU & 9.1 \\
\hline $\begin{array}{c}\text { Sawla - } \\
\text { Wa }\end{array}$ & SA2WA & 0.2550 & WA & 2211 \\
\hline $\begin{array}{c}\text { Wa - } \\
\text { Tumu }\end{array}$ & WA1TM & 0.5800 & TUMU & 8.6 \\
\hline $\begin{array}{c}\text { Tumu - } \\
\text { Bolga }\end{array}$ & TM5BG & 0.0178 & & \\
\hline
\end{tabular}

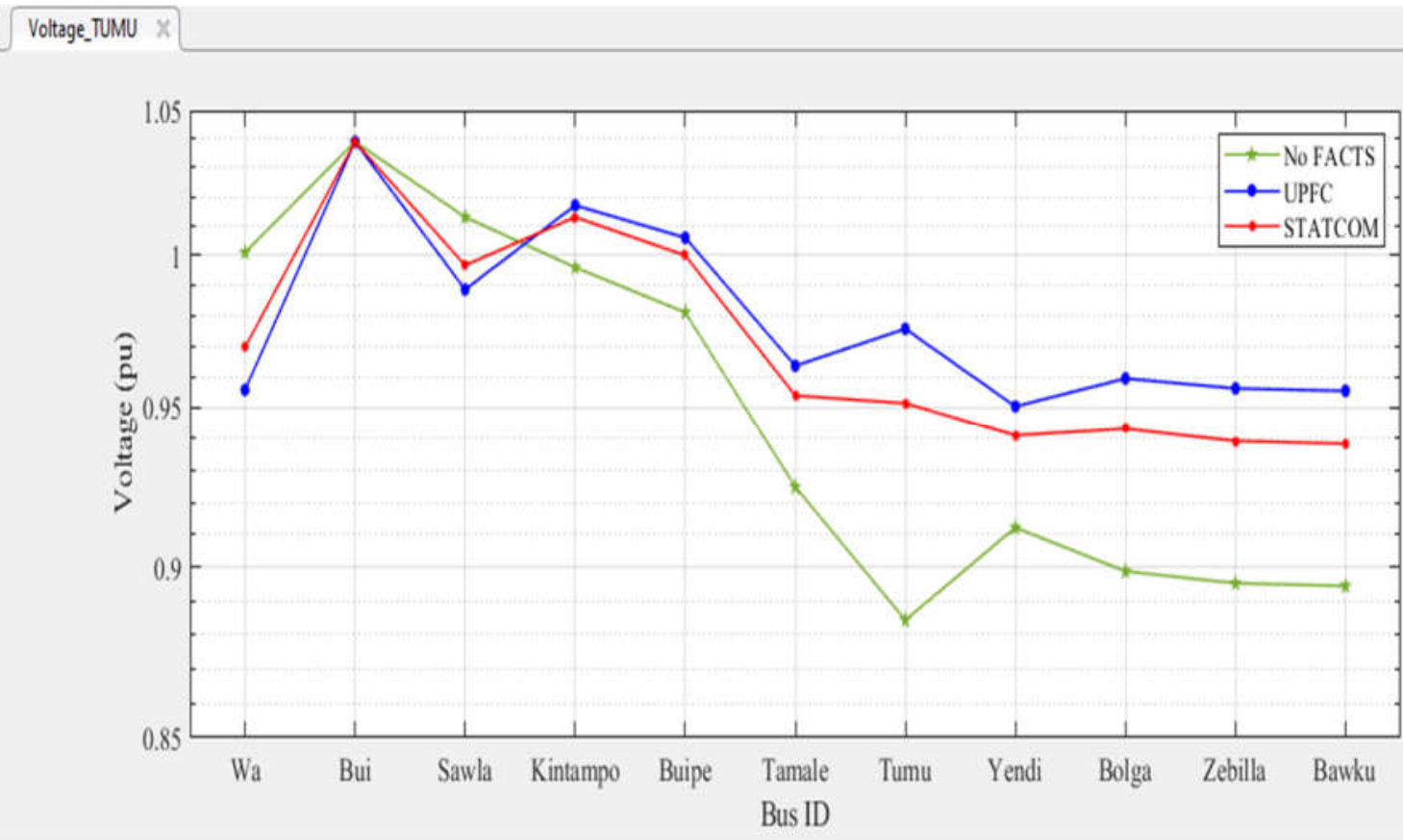

Fig. 4 Results of voltage profile with UPFC, STATCOM and with no device in circuit

From Table 1, a conclusion can be drawn that the TUMU bus, which is the weakest and also linking the critical line is suitable for the 
placement of the UPFC. The UPFC is placed at the optimal location and series of simulations are performed to determine its performance.

As evident from Fig. 4, the UPFC produced voltage levels within a stability limit of 5\% p.u. for all buses in the network. The bus voltage at Tumu improved significantly from 0.8843 p.u. to 0.9756 p.u. The lowest bus p.u. voltage of 0.9504 recorded in the network for the UPFC is found at Yendi. This lowest value at Yendi was as a result of the radial line connecting the Yendi bus, and more importantly, this bus is most distant from the Tumu BSP. When the
STATCOM was connected to the same bus, four of its buses (Yendi, Bolga, Zebilla and Bawku) had voltages below the stability limit of $5 \%$ p.u.

Fig 5 presents the results on active power loss for all three scenarios. With no FACTS device connected, the active power loss in the system was $13.40 \mathrm{MW}$. Connecting the STATCOM to the system reduced the power loss to $12.16 \mathrm{MW}$, whilst the UPFC gave a better improvement by further reducing the active power loss to $10.39 \mathrm{MW}$

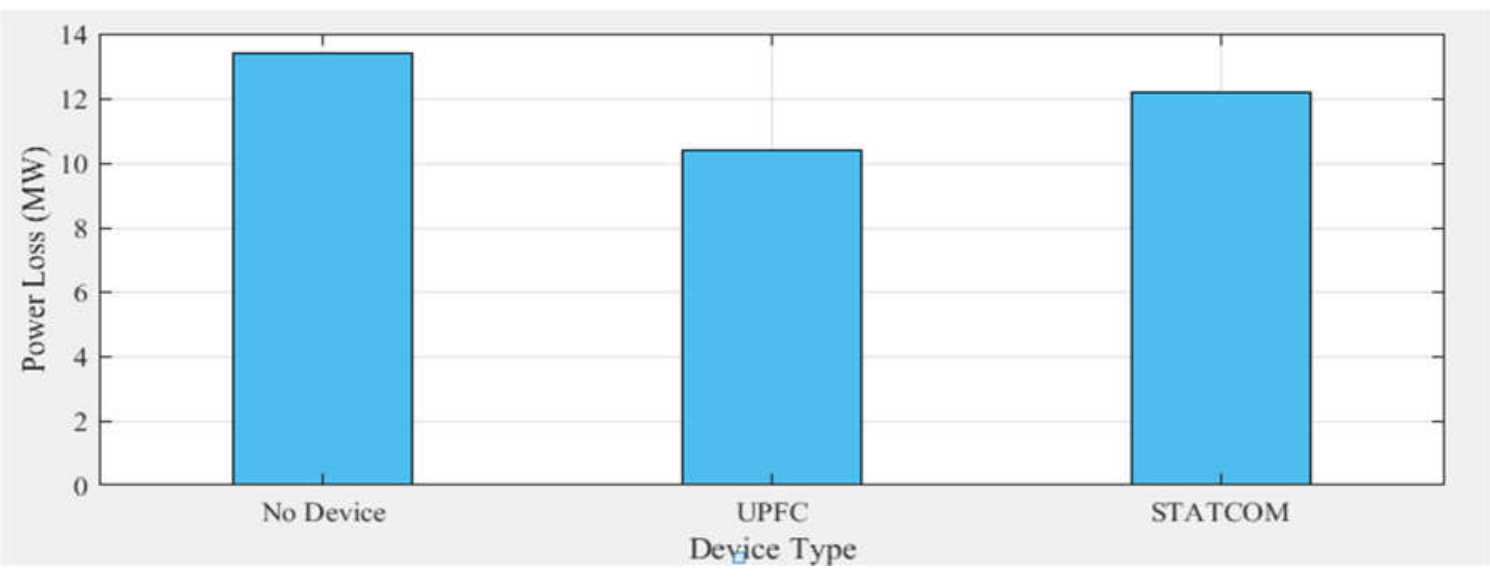

Fig. 5 Active power loss of the system with and without FACTS devices

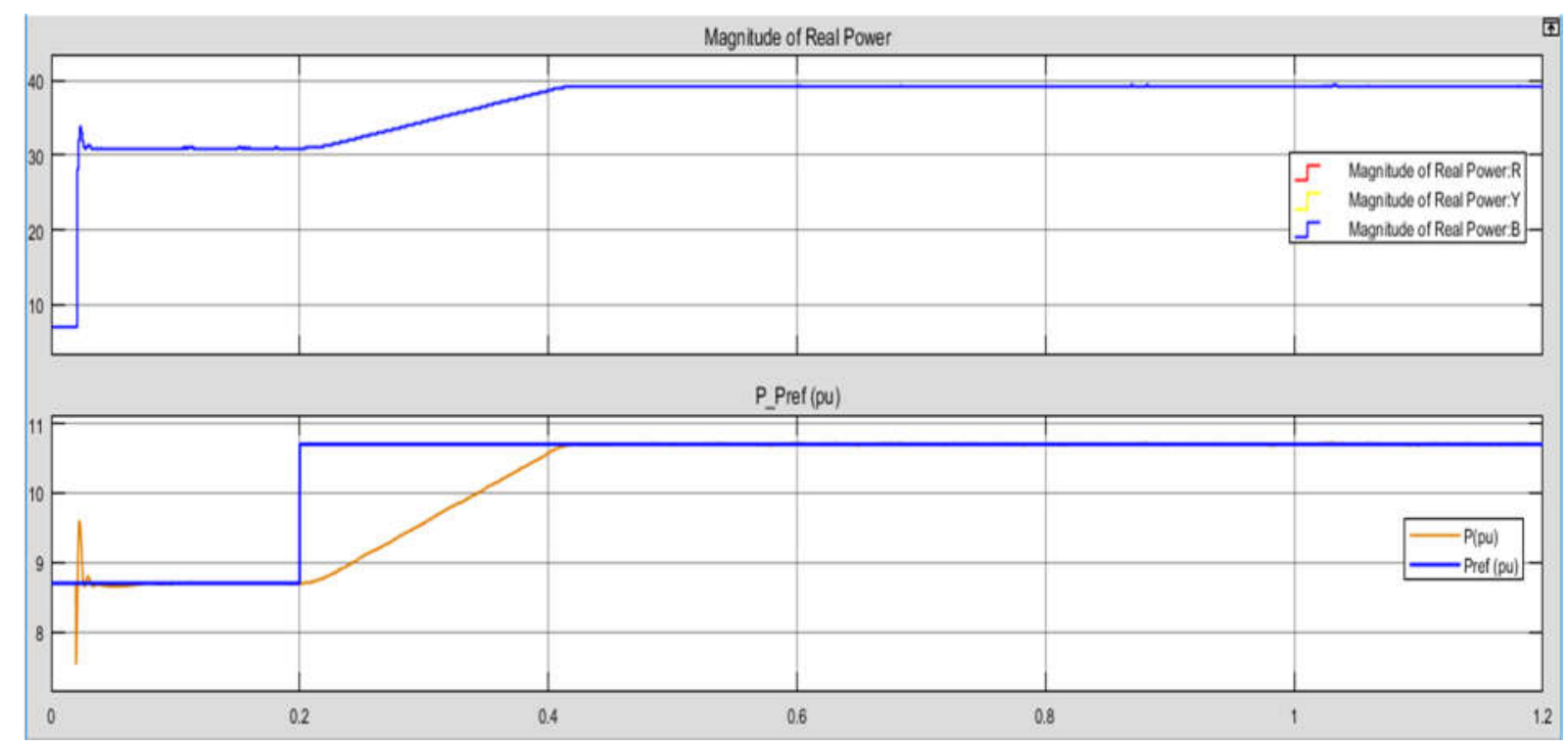

Fig. 6 Simulation results on active power flow control of the UPFC 
The performance of the UPFC controllers are also verified using simulations. Scopes were connected at various outputs to interpret the results on each controller. In the power flow control mode, the active power flow on the network bus linking the UPFC bus was realised to be $5.4 \mathrm{MW}$. At time $0.025 \mathrm{~s}$, when the UPFC was brought into circuit, the power capability of the connecting line increased to $32.50 \mathrm{MW}$ as can be seen in the first trace of Fig. 6.

A step change introduced into the reference power from 8.7 p.u. to 10.7 p.u. at $0.2 \mathrm{~s}$ causes the UPFC to respond by increasing the active power transfer from $32.50 \mathrm{MW}$ to $40 \mathrm{MW}$.

The action of the reactive power controller is similar to the active power controller. From Fig 7, the UPFC initially produced a reactive power control of 3.4 MVAr. A step change introduced to the reactive power controller caused the UPFC to increase its reactive power transfer to $7.8 \mathrm{MVAr}$ on the connecting bus.

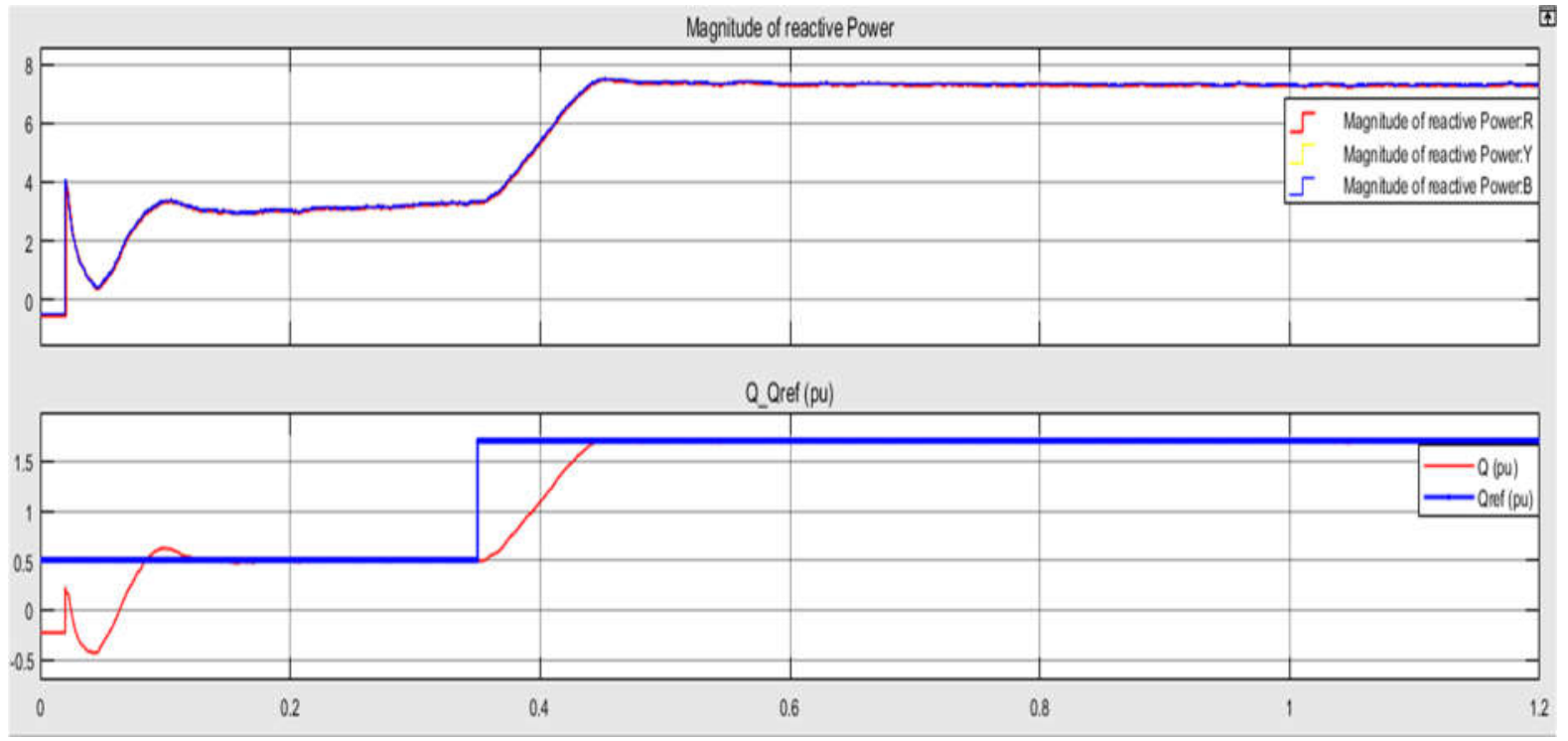

Fig. 7 Simulation results on reactive power flow control of the UPFC

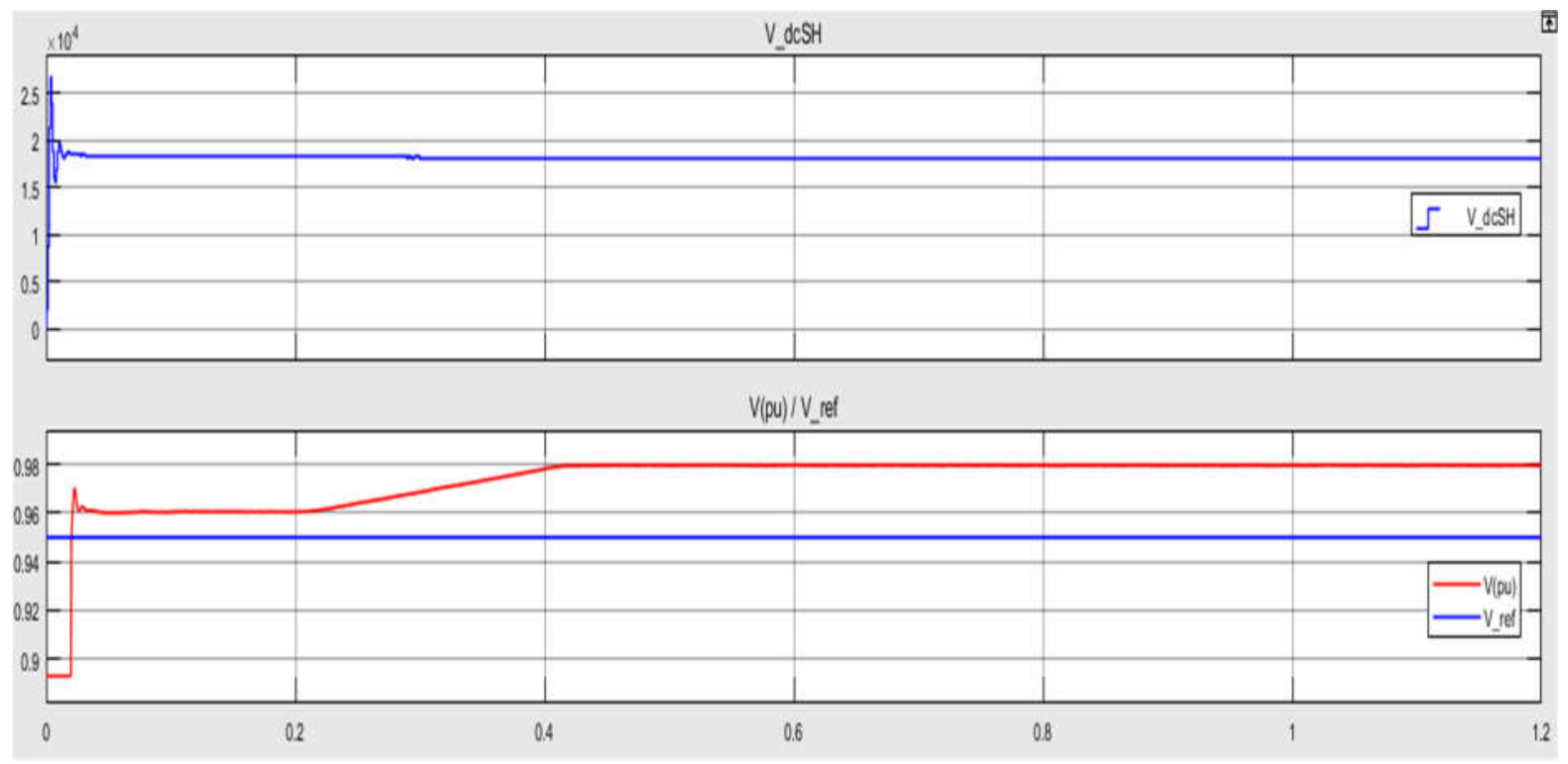

Fig. 8 Simulation results on bus voltage and shunt side DC voltage

The voltage improvement of the network is achieved by the STATCOM and UPFC controllers. At the start of the simulations, the voltage realised on the connecting bus was 0.89 
p.u. and the initial action of the UPFC increased the bus voltage to 0.96 p.u. When the active power flow on the line was increased, the voltage level on the connecting bus also increased to a new value of 0.98 p.u. as found in Fig. 8.

It is evident from the results that an increase in active power transfer on a transmission line has a positive effect on bus voltage. The DC capacitor voltage on the shunt side remained constant throughout the entire simulations.

\section{Conclusion}

A 161-kV configuration of an UPFC was successfully modelled using SimPowerSystems. The device was optimally placed using FVSI and MLA. Connecting the UPFC in circuit produced voltage levels within a stability limit of $5 \%$ p.u. for all buses in the network. The active power loss in the system was significantly reduced from 13.40 MW to $10.39 \mathrm{MW}$ when the UPFC was placed in circuit.

\section{References}

[1] S. D. Choudante, and A. A. Bhole, "A review: voltage stability and power flow improvement by using UPFC controller", International Conference on Computation of Power, Energy, Information and Communication, Melmaruvathur, India, pp. $462-465,2018$.

[2] N. Voropai, S. Podkovalnikov, and K. Osintsev, "From interconnections of local electric power systems to global energy interconnection", Global Energy Interconnection, vol. 1, issue 1, pp. $4-$ 10, 2018.

[3] T. Kerdphol, F. Rahman, and Y. Mitani, "Virtual inertia control application to enhance frequency stability of interconnected power systems with high renewable energy penetration", Energies, vol. 11, issue 4, pp. 1 - 16, 2018.

[4] L. L. Grigsby, The electric power engineering handbook - five volume set, CRC press, Boca Raton, Florida, USA, 438 pp, 2018.

[5] K. R. Padiyar, and A. M. Kulkarni, Dynamics and control of electric transmission and microgrids, Wiley Publishers, West Sussex, UK, $2^{\text {nd }}$ edition, 485 pp., 2019.

[6] M. Banafer, and M. Biswal, "Investigation of power system cascading failure and the causes", International Conference on Power, Energy and Environment: Towards Smart Technology, Shillong, India, pp. $1-5,2018$.

[7] J. Modarresi, E. Gholipour, and A. Khodabakhshian, "A comprehensive review of the voltage stability indices", Renewable and Sustainable Energy Reviews, vol. 63, no. 1, pp. $1-12$, 2016.

[8] P. Thannimalai, R. R. Raman, P. Nair, and K. Nithiyananthan, "Voltage stability analysis and stability improvement of power system", International Journal of Electrical \& Computer Engineering, vol. 5, issue 2, pp. $2088-8708,2015$.

[9] H. Kianersi, and H. Asadi, "Voltage stability improvement by using FACTS elements with economic consideration", Ciência e Natura, vol 37, pp. $162-167,2015$.

[10] G. Deb, K. Chakraborty, and S. Deb, "Voltage stability analysis using reactive power loading as indicator and its improvement by FACTS device" In 2016 IEEE $1^{\text {st }}$ International Conference on Power Electronics, Intelligent Control and Energy Systems, Delhi, India, pp. 1- 5, 2016.

[11] W. Aslam, Y. Xu, A. Siddique, and F. M. Albatsh, "Implementation of series FACTS devices, SSSC and TCSC to improve power system stability", $13^{\text {th }}$ IEEE Conference on Industrial Electronics and Applications, Wuhan, China, pp. 2291-2297, 2018.

[12] A. K. Dwivedi, and S. Vadhera, "Reactive power sustainability and voltage stability with different FACTS devices using PSAT", 6th International Conference on Signal Processing and 
Integrated Networks, Uttar Pradesh, India, pp. $248-253,2019$

[13] M. Yesilbudak, S. Ermis, and R. Bayindir, "Investigation of the effects of FACTS devices on the voltage stability of power systems", IEEE $6^{\text {th }}$ International Conference on Renewable Energy Research and Applications, San Diego, California, pp. 1080 - 1085, 2017.

[14] S. Rotra, I. Kaur, and K. K. Sharma, "Analysis of active and reactive power and voltage control in the power structure with the help of unified power flow controller", Cognitive Informatics and Soft Computing, Springer, Singapore pp. 485 - 494, 2019.

[15] L. Hongmei, S. Haobo, W. Qi, and Z. Yunfan, "Research on the installation location and parameter configuration method of upfc in energy internet, proceedings of the IEEE conference on energy internet and energy system integration, Beijing, China, pp. 1 - 6, 2017.

[16] T. P. G. T. A. Priyankara, M. J. L. R., Fernando, I. A. K. Sandeepa, N. M. K. D. Bandara, H. W. D. Hettiarachchi, and K. T. M. U. Hemapala, "Design, simulation and implementation of a upfc" for transmission line model, in 2017 innovations in power and advanced computing technologies, Tamil Nadu, India, pp. 1- 6, 2017.

[17] S. Kannan, and S. J. Miah, "Integration of knowledge management and business intelligence for lean organisational learning by the digital worker", in: applying business intelligence initiatives in healthcare and organisational settings, IGI Global Publishers, Glasgow, Scotland, $1^{\text {st }}$ edition, pp. 130 $-140,2019$.

[18] F. M. Albatsh, S. Ahmad, S. Mekhilef, H. Mokhlis, and M. A. Hassan, "Optimal placement of unified power flow controllers to improve dynamic voltage stability using power system variable based voltage stability indices", PLOS ONE, vol. 10, no. 4, pp. 1 - 32, 2015.

[19] B. Singh, P. Tiwari, and S. N. Singh, "Enhancement of power system performances by optimally placed facts controllers by using different optimization techniques in distribution systems, $5^{\text {th }}$ IEEE Uttar Pradesh Section International Conference on Electrical, Electronics and Computer Engineering, Gorakhpur, Pradesh, India, pp. $1-7$, 2018.

[20] D. Sen, M. Gupta, M. Shegaonkar, S. Das, and P. Acharjee, "Optimal location determination of upfc based on technoeconomic criteria and security constraints", In 2018 International

Conference on Power Energy, Environment and Intelligent Control, Noida, India. pp. 534 - 539, 2018.

[21] A. Thamilmaran, and P. Vijayapriya, "Location of UPFC based on critical bus ranking index", In Soft Computing for Problem Solving, Springer, Singapore pp. $795-805,2020$.

[22] J. E. Essilfie, J. Tlusty, and P. Santarius, "Using SVC to improve voltage stability of the Ghana power network", Przegląd Elektrotechniczny, vol. 89, no. 5, pp. 47 - 53, 2013.

[23] J. E. Essilfie, Z. Muller, J. Svec, and J. Tlusty, "STATCOM effect on voltage stability in Ghanaian electrical grid", Proceedings of the $15^{\text {th }}$ IEEE International Scientific Conference, Brno, Czech Republic, pp. 235 - 240, 2014.

[24] Mathworks, simpowersystems ${ }^{\mathrm{TM}}$, user's guide, The MathWorks Inc., Natick, Massachusetts, 78 pp, 2016.

[25] V. M. Perelmuter, Electrotechnical systems: simulation with simulink and simpowersystem, CRC Press, Florida, USA, 1st edition, 441 pp., 2013.

[26] M. Taleb, A. Salem, A. Ayman, M. A. Azma, and M. A. Abido, "Advanced 
Technique for Optimal Allocation of Static Var Compensators in Large-scale Interconnected Networks", In 2017 Annual Conference of the IEEE Industrial Electronics Society, Beijing, China, pp. $73-78,2017$. 